\title{
고무사출성형의 적정설계
}

\author{
이은주 · 임광희 *, · 부타이지양* \\ 경북대학교 화학공학과 \\ 702-701 대구광역시 북구 산격동 1370 번지 \\ 대구대학교 화학공학과 \\ 712-714 경북 경산시 진량읍 내리리 15 \\ (2010년 9월 27일 접수, 2010년 10월 30일 채택)
}

\section{Optimum Design of Rubber Injection Molding Process}

\author{
Eun Ju Lee, Kwang-Hee Lim*, ${ }^{*}$ and Vu Tai Giang* \\ Department of Chemical Engineering, Kyungpook National University, 1370, Sankyeok-dong, Buk-gu, Daegu 702-701, Korea \\ Department of Chemical Engineering, Daegu University, 15 Naeri-ri, Jillyang-ep, Gyungsan-si, Gyeongbuk 712-714, Korea \\ (Received 27 September 2010; accepted 30 October 2010)
}

\begin{abstract}
요 약
$\mathrm{K}$ 사의 고무 사출성형에 있어서 애로사항인 등속조인트 부트(boots)의 크랙(crack) 발생 등의 문제점을 해결하기 위 하여, 상용 CAE 프로그램인 MOLDFLOW(Ver. 5.2)를 이용한 전산모사를 수행하여 적정금형설계를 도출하고 적정작 업조건을 구축하였다. 그 결과 크랙의 발생 원인은 크랙이 발생하는 위치에 형성되는 weld 및 meld line의 형성 때문 이고, 또한 크랙이 발생하는 위치에서의 가류(curing)가 불완전한 것이 확인되었다. 이와 같은 weld 및 meld line의 형 성을 방지하기 위해서 게이트(gate)의 위치를 변경하고 최적위치에 설계함으로써, 유동선단(melt front)의 충돌 또는 수 지흐름의 만남을 최소화하는 충전패턴(fill pattern)을 형성하고 부트 안쪽 하단의 크랙 발생을 방지하였다. Weld 및 meld line과 에어트랩(air trap) 불량이 가장 큰 게이트 위치는 각각 최적 게이트위치를 기준으로 서로 정반대 방향임이 관찰 되었다. 한편 몰드(mold)의 온도를 $170^{\circ} \mathrm{C}$ 로 유지하게 함으로써 크랙이 발생했던 위치에 가류조건을 만족시켰다.
\end{abstract}

\begin{abstract}
The optimum mold design and the optimum process condition were constructed upon executing process simulation of rubber injection molding with the commercial CAE program of MOLDFLOW (Ver. 5.2) in order to solve the process-problems of $\mathrm{K}$ company relating to cracks, which occurs at the inner cavity wall of $\mathrm{C}$. V. joint boots. As a result it was confirmed that the real cracks occurs at the exactly same position of the cavity as exhibits the defects of weld and meld line and unsatisfactory curing according to the result of simulation. In order to prevent the occurrence of weld and meld line at the defect-position, the location of gate was altered to the optimum position of the cavity. Consequently the filling pattern was established to minimize the degree of the melt-fronts confronting or the melt-flows melding to prevent the occurrence of weld and meld line at the defect-position. It was observed that both gate-positions to maximize the degree of the formation of weld and meld line and air traps are located, respectively, in opposite direction each other with reference to the optimum gate position. In addition, the temperature of mold was raised by $10^{\circ} \mathrm{C}$ and maintained at $170{ }^{\circ} \mathrm{C}$ for satisfactory curing.
\end{abstract}

Key words: Rubber Injection Molding, C. V. Joint Boots, Crack, Process simulation, Weld and Meld Line, Air Trap, Curing

\section{1. 서 론}

등속조인트는 변속기나 액슬의 차동기어에서 바퀴로 동력을 전달 하는 부품으로서, 조향이나 서스펜션에 의한 회전 중심의 변화에도 등속성을 유지되도록 한다. 볼, 케이지, 인너레이스, 스파이더, 롤러 등의 부품들이 그리스로 윤활이 되어 움직이기 때문에 작동부품을 고무 부트로 둘러싸서 기밀성을 유지한다[1]. 등속조인트 부트는 조

\footnotetext{
${ }^{\dagger}$ To whom correspondence should be addressed.

E-mail: khlim@daegu.ac.kr
}

향장치에 의한 차축의 회전운동을 전달하는 차축연결부위인 등속조 인트를 보호하는 기능을 하며[2], 내부에 윤활유를 채워 장시간 윤활 이 가능하도록 하는 역할을 하는 부품이다[3].

사출성형에 있어서 금형 내 캐비티 안에서의 유동해석을 위한 $\mathrm{CAE}$ 기술을 활용한 수치해석 기법에 대한 연구는 지속적으로 연구 되어 왔다[4-7]. 금형 캐비티 모델은 전산모사를 수행하는 데 필요한 수치해석법인 finite element법(FEM), finite difference법(FDM), boundary element법(BEM) 및 finite volume법(FVM) 등에 적용하는 데에 최적화되어야 한다[8]. 대부분의 상용 사출모사 패키지는 Hele- 
Shaw approximation[7]을 기본으로 하는데, 대부분의 사출부품이 얇 은 벽이기 때문에 mid-plane과 두께방향에서 흐름과 열적효과를 분 리(decouple)할 수 있기 때문에 소위 2.5 차원 접근이 가능하다[9]. Mid-plane 모델은 2차원인 면에 의한 3차원 형상 구현을 하기 위하 여 생성되므로, 수치해석 상의 두께가 mid-plane 메쉬를 구성하는 모 든 납작하고 평평한 요소에 주어진다. 이러한 상용 사출모사 패키지 중에서 널리 알려진 MOLDFLOW(Ver. 5.2)의 MPI/reactive molding 모듈에서 reactive molding 공정모델링은 MPI 열가소성수지 사출성 형모델링과 1) 모델 및 메쉬 요구조건이 동일하며, 2) 금형과 수지와 의 열전달이 존재하고, 3) 대부분의 수지가 shear thinning 거동을 보 이는 점에서 공통점이 있다. 그러나 열경화성수지는 열가소성수지와 다르게 처리해야하는 특성이 있으므로, 1) 게이트 입구에서 수지용 융점은 금형 벽 온도보다 낮으며, 2) 금형 벽으로부터 처음에는 수지 로 열전달이 이루어지고, 3) 수지온도가 기준점에 도달하면 가교반 응이 시작되고, 4)가교반응열이 발생하여 수지 온도는 금형 벽 온도 를 초과할 수 있으며, 5) 점도는 온도, 전단율(shear rate) 뿐만 아니 라 가교정도에 대한 함수인 점에서 MPI 열기소성수지 사출성형모델 링과 다르다.

본 연구에서는 등속조인트 부트(이하 부트) 제작을 위한 K사의 고무사출성형공정을 상용 소프트웨어 패키지인 MOLDFLOW (Ver. 5.2)의 MPI/reactive molding 모듈을 사용하여 모사하고 그 유동해석 결과를 실제 $\mathrm{K}$ 사의 고무사출성형 결과와 비교하였다. 그 러한 결과 비교를 통하여 부트의 적정 금형설계 및 작업조건을 제 시하였다.

\section{2. 실 험}

\section{2-1. 실험 방법}

본 연구의 방법으로는 부트의 사출성형을 위하여 상용 소프트웨 어 패키지인 MOLDFLOW(Ver. 5.2)의 MPI/reactive molding 모듈을 사용하여 부트 형태를 갖춘 fusion 모델링을 수행하였다. Table 1과 같은 사출온도(성형온도), 금형온도, 사출시간 및 가류(curing) 시간 등의 주어진 충전 및 가교과정을 포함한 사출성형 공정조건 하에서, MOLDFLOW(Ver. 5.2)의 데이터뱅크로부터 입력되는 금형 캐비티 내로 충전되는 충전물의 물성 데이터와 런너 배치(configuration) 또 는 게이트 및 에어벤트 구의 위치 선정 등을 가지고 고무사출성형의 전산모사를 수행하였다. 그 결과 부트의 사출성형을 위한 적정금형 설계를 수행하고 고무사출성형 공정의 적정작업조건을 구축하였다.

\section{2-1-1. 모델링}

본 연구의 금형 충전모델은 일반화된 Hele-Shaw 모델[7]을 활용 하고, 수치 해석은 hybrid FEM/FDM법을 기본으로 하였다. FEM법 에서의 요소(element)는 일반적으로 사용되는 삼각형 요소 형태의

Table 1. Process conditions to prepare boots by injection molding process

\begin{tabular}{lll}
\hline \hline Process condition & Description & Unit \\
\hline Mold temperature & 160 & ${ }^{\circ} \mathrm{C}$ \\
Melt temperature & 85 & ${ }^{\circ} \mathrm{C}$ \\
Injection time & 25 & $\mathrm{sec}$ \\
curing time & 240 & $\mathrm{sec}$ \\
Machine pressure limit & $21.6(220)$ & $\mathrm{MPa}\left(\mathrm{kg}_{f} / \mathrm{cm}^{2}\right)$ \\
Thermoset material & Natural rubber (EDS 13/78 IRHD) \\
\hline
\end{tabular}

shell mesh를 사용하였고, 각 요소의 aspect ratio는 1.3 1.5의 범위에 서 설정하였다. 이러한 요소분할(meshing) 조건에 맞게 형성한 표면 (surface)에 스프루, 런너, 게이트 등을 모델링하였다.

2-1-1-1. 지배방정식

Mid-plane 모델 경우에 MPI/reactive molding 흐름분석에 사용되는 지배방정식은 Chiang et al.[10]과 Turng과 Wang[11]의 것과 유사하 며 압축성유체의 continuity식을 적용하였다.

2-1-1-1-1. 모멘텀(Momentum)식

Inertia항을 무시하고 thin cavity approximation을 이용한 $\mathrm{x}$ 및 $\mathrm{y}$ 각 방향의 momentum식은 다음과 같다.

$$
\begin{aligned}
& 0=\frac{\partial}{\partial z}\left(\eta \frac{\partial u}{\partial z}\right)+\frac{\partial p}{\partial x} \\
& 0=\frac{\partial}{\partial z}\left(\eta \frac{\partial v}{\partial z}\right)+\frac{\partial p}{\partial y}
\end{aligned}
$$

이 식에서 $\eta, \mathrm{p}, \mathrm{u}, \mathrm{v}$ 는 각각 점도, 압력, $\mathrm{x}$ 및 $\mathrm{y}$ 각 방향의 속도이고, $\mathrm{z}$ 방향은 정압이다.

\section{2-1-1-1-2. 에너지(Energy)식}

Thin cavity를 가정하고 전단과 가교로 인한 발생열을 포함하는 에 너지식은 다음과 같다.

$$
\rho \mathrm{C}_{p}\left(\frac{\partial \mathrm{T}}{\partial \mathrm{t}}+\mathrm{u} \frac{\partial \mathrm{T}}{\partial \mathrm{x}}+\mathrm{v} \frac{\partial \mathrm{T}}{\partial \mathrm{y}}+\mathrm{w} \frac{\partial \mathrm{T}}{\partial \mathrm{z}}\right)=\frac{\partial}{\partial \mathrm{z}}\left(\mathrm{k} \frac{\partial \mathrm{T}}{\partial \mathrm{z}}\right)+\eta \dot{\gamma}^{2}+\frac{\mathrm{d} \alpha}{\mathrm{dt}} \mathrm{H}
$$

이식에서 $\mathrm{C}_{p}, \mathrm{~T}, \mathrm{k}, \eta, \dot{\gamma}, \alpha$ 및 $\mathrm{H}$ 는 각각 열용량, 온도, 열전달계수, 점도, 전단율(shear rate), 가교도 및 가교로 인한 열생성을 나타낸다.

\section{2-1-1-1-3. 가류(Curing)식}

가교시간에 따라서 금형 캐비티 내에서 가교가 진행되는 가교도 $(\alpha)$ 를 구하는 가류식은 다음과 같다.

$$
\begin{aligned}
& \left(\frac{\partial \alpha}{\partial \mathrm{t}}+\mathrm{u} \frac{\partial \alpha}{\partial \mathrm{x}}+\mathrm{v} \frac{\partial \alpha}{\partial \mathrm{y}}+\mathrm{w} \frac{\partial \alpha}{\partial \mathrm{z}}\right)=\left(\mathrm{K}_{1}+\mathrm{K}_{2} \alpha^{\mu}\right)(1-\alpha)^{v} \\
& \mathrm{~K}_{1}=\mathrm{A}_{1} \exp \left(-\mathrm{E}_{1} / \mathrm{T}\right) \\
& \mathrm{K}_{2}=\mathrm{A}_{2} \exp \left(-\mathrm{E}_{2} / \mathrm{T}\right)
\end{aligned}
$$

이식에서 $\mu, \mathrm{v}, \mathrm{A}_{1}, \mathrm{~A}_{2}, \mathrm{E}_{1}, \mathrm{E}_{2}$ 는 fitting 상수이며, $\mathrm{u}, \mathrm{v}, \mathrm{w}$ 는 $\mathrm{x}, \mathrm{y}, \mathrm{z}$ 각 방향의 속도이다.

2-1-1-1-4. 반응 점도(reactive viscosity)식

금형 캐비티 내부로 충전된 충전물은, 가류 온도 이상으로 주어진 금형 벽으로부터 열교환이 발생하여 전항 2-1-1-1-3에서 언급된 것 처럼 가류가 진행된다. 가교가 진행되면서 가교도 $(\alpha)$ 가 커지며 변화 하는 점도를 예측하기 위하여 다음과 같은 reactive viscosity 모델이 사용되었다.

$$
\begin{aligned}
& \eta(\alpha, \mathrm{T}, \dot{\gamma})=\frac{\eta_{o}(\mathrm{~T})}{1+\left(\frac{\eta_{o}(\mathrm{~T})}{\tau^{*}} \dot{\gamma}\right)^{1-n}}\left(\frac{\alpha_{g}}{\alpha_{g-\alpha}}\right)^{\left(c_{1}+c_{2} \alpha\right)} \\
& \eta_{o}=\mathrm{B} \exp \left(\frac{\mathrm{T}_{b}}{\mathrm{~T}}\right) \\
& \text { 이식들에서 } \alpha_{g} \text { 는 각각 가교가 진행되어 충전물 유동이 멈추고 점 } \\
& \text { 도가 무한대에 도달하는 겔화점(gelation conversion)이며, 그 외의 모 } \\
& \text { 델계수인 } \mathrm{n}, \tau^{*}, \mathrm{~B}, \mathrm{~T}_{b}, \mathrm{c}_{1} \text { 및 } \mathrm{c}_{2} \text { 는 데이터 fitting 상수들이다. }
\end{aligned}
$$




\section{2-1-1-1-5. 경계조건}

금형 벽 $(\mathrm{z}=0, \mathrm{~h})$ 에서 충전물 흐름의 no slip 조건 및 주어진 금형 벽 온도 $\left(\mathrm{T}_{w 1}\right)$ 로서 경계조건은 $\mathrm{u}=0, \mathrm{v}=0, \mathrm{w}=0, \mathrm{~T}=\mathrm{T}_{w 1}$ 과 같이 나타내 어진다. 게이트 입구에서 온도는 일정하며 압력은 균일하고 시간의 함수로 설정되었다. 또한 금형 캐비티 벽에서 수직방향으로 압력 구 배는 영이고, 유동선단(flow front)에서의 압력은 영으로 설정되었다.

\section{2-2. 실험 대상}

\section{2-2-1. K사 부트의 제조현황 및 문제점}

Fig. 1과 같이 K사가 제조한 부트 제품에서 Fig. 2와 같이 크랙이 게이트 반대편에 검정 화살표 방향으로 짙게 발생되고 있다. 게이트 반대편에 에어 벤트(air vent)를 주었고, 오버프로우(overflow)를 주 었음에도 불구하고, 여전히 크랙이 제거되지 않고 있다.

2-2-2. 모델링 및 $\mathrm{CAE}$ 모사를 통한 공정분석

$\mathrm{K}$ 사에서 제조되는 부트의 크랙 발생위치 및 발생원인 규명 및 크랙 제거를 위한 문제해결(trouble shooting)을 하고자한다. MOLDFLOW (Ver. 5.0)의 MPI/reactive molding 모듈을 사용하여 $\mathrm{K}$ 사 공정조건과 같은 8 개의 캐비티, 스프루(sprue), 런너 및 게이트를 포함한, K사에 서 생산하고 있는 부트의 fusion 모델링을 Fig. 3과 같이 수행하였고 적용되는 공정조건은 Table 1과 같다. $\mathrm{K}$ 사의 부트 사출성형재료로서 주로 클로로프렌 고무 또는 천연고무를 사용하는데, 카본블랙을 혼

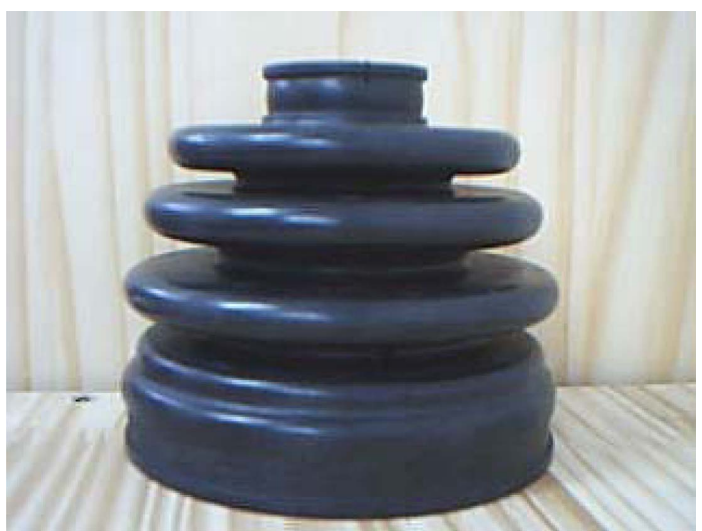

Fig. 1. Boots produced by K company.

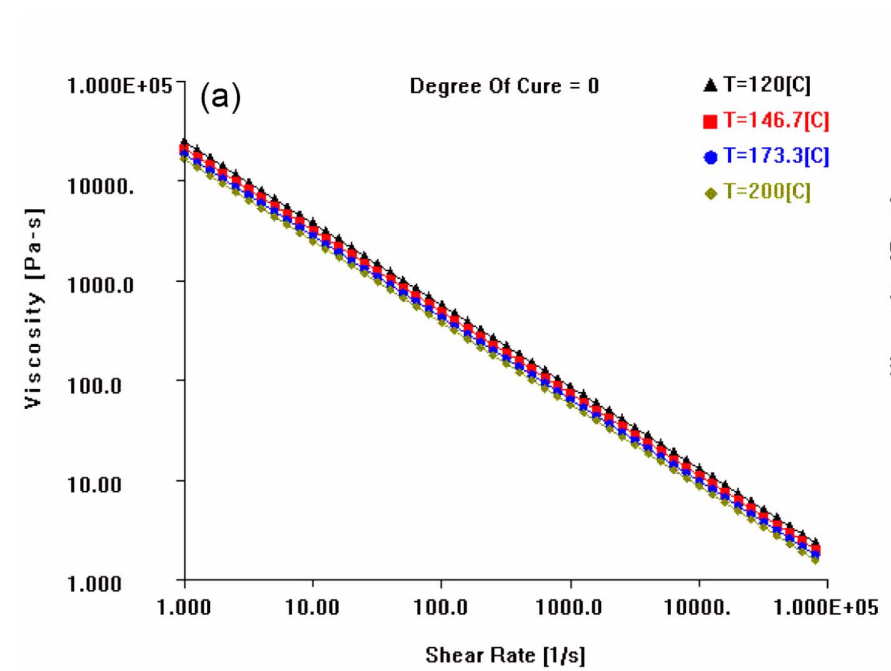

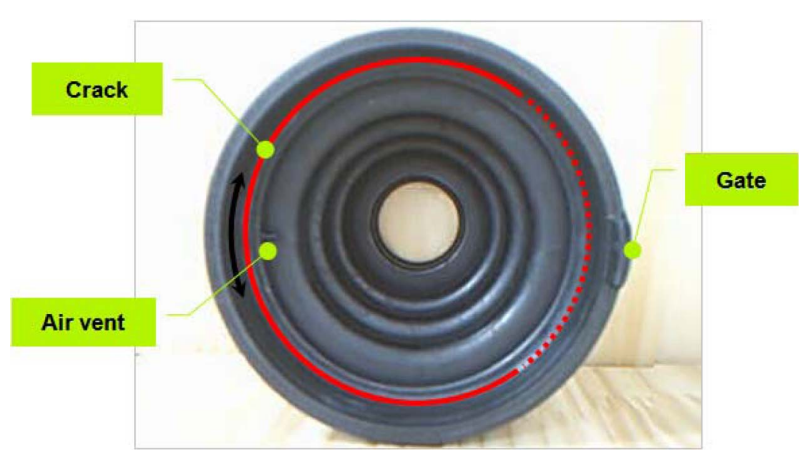

Fig. 2. Locations of cracks observed in the boots produced by $K$ company and the positions of both gates and air vent from its mold design.

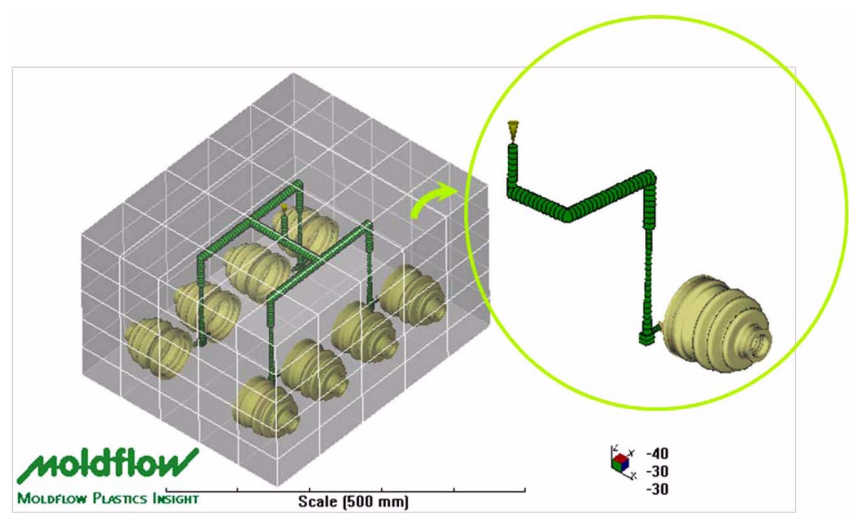

Fig. 3. Modeling for boots produced by K company.

합하여 경도(IRHD)가 78이고 용융점이 85인 천연고무를 가황시키 는 가류공정에서 가황고무의 점도를 예측하는 반응점도식의 모델계 수인 $\alpha_{g}, \mathrm{n}, \tau^{*}, \mathrm{~B}, \mathrm{~T}_{b}, \mathrm{c}_{1}$ 및 $\mathrm{c}_{2}$ 의 값들은 각각 $0.1,0.1815,0.1 \mathrm{~Pa}$, $9.86552 \times 10^{22} \mathrm{~Pa} \mathrm{sec}, 5160.32 \mathrm{~K}, 1$ 및 0 이었다. 따라서 가교도 $(\alpha)$ 가 "0"일 때 전단율(shear rate), $1 / \mathrm{s}$ 이상에서 금형온도 $\left(160^{\circ} \mathrm{C}\right)$ 근처 $120,146.7,173.3$ 및 $200{ }^{\circ} \mathrm{C}$ 각각의 온도에서 Fig. 4(a)에서와 같이 power law 유체 거동 특성을 보였다. 한편 클로로프렌 고무인 네오 프렌의 경우는 가류공정에서 가황고무의 점도를 예측하는 반응점도

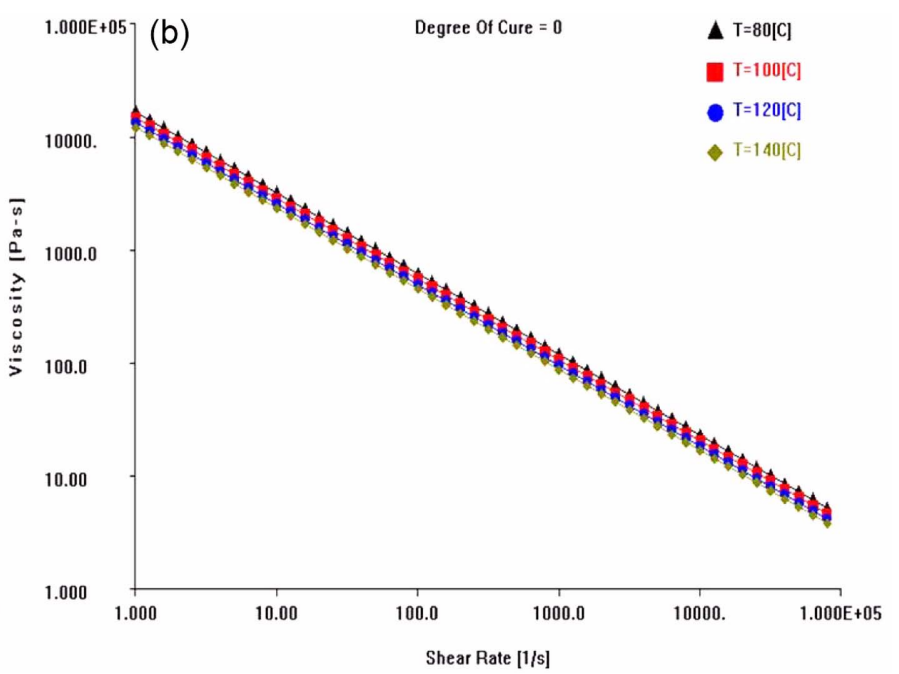

Fig. 4. Viscosity-prediction with zero degree of cure at various temperatures: a) Natural rubber (EDS 13/78 IRHD); b) Chloroprene rubber (Neoprene/GW). 
식의 모델계수인 $\alpha_{g}, \mathrm{n}, \tau^{*}, \mathrm{~B}, \mathrm{~T}_{b}, \mathrm{c}_{1}$ 및 $\mathrm{c}_{2}$ 의 값들은 각각 $0.1,0.2356$, $0.1 \mathrm{~Pa}, 9.92115 \times 10^{13} \mathrm{~Pa} \mathrm{sec}, 2676.15 \mathrm{~K}, 1$ 및 0 이었고, 가교도 $(\alpha)$ 가 "0"일 때 전단율(shear rate), $1 / \mathrm{s}$ 이상 및 $80,100,120$ 및 $140{ }^{\circ} \mathrm{C}$ 각각의 온도에서 Fig. 4(b)에서와 같이 power law 유체 거동 특성을 보였다.

\section{3. 결과 및 고찰}

Fig. 5는 K사의 사출조건(Table 1)에 의한 부트의 사출성형모사에 서 에어트랩(air trap) 모사결과이다. 에어트랩은 Fig. 2에서의 크랙 발생분포와 수직방향인 화살표 방향으로 분포를 보이고 있으므로, 에어트랩이 크랙 발생의 원인이 아님이 유추되어진다. 이것이 Fig. 2 에서와 같이 게이트 반대편에 에어 벤트를 주었음에도 불구하고 크 랙이 제거되지 않았던 이유라고 사료된다. 한편 Fig. 6은 K사의 사출 조건(Table 1)에 의한 부트의 사출성형모사에서 weld 및 meld line의 모사결과인데, No. 1은 주요 weld 및 meld line을 나타내고 No. 2-5 는 상대적으로 미미하게 발생되는 weld 및 meld line을 도시한다. 이
와 같이 Fig. 2에서 K사 부트의 결함인 크랙의 실제 발생위치와, Fig. 6과 같은 모사결과에서 얻은 주요 weld 및 meld line(No. 1)의 발생 위치가 일치하였다. 따라서 부트의 크랙 발생원인은 weld 및 meld line임이 확인되었다.

이와 같은 weld 및 meld line 형성의 추이를 관찰하기 위하여 $\mathrm{K}$ 사 의 사출조건으로 부트의 사출성형모사에서 충전시간(fill-time) 분석 및 가류층 비율(cured layer fraction) 분석을 Figs. 7 및 8 과 같이 각 각 수행하였다. Fig. 7의 도시된 타원 내의 충전 패턴과 같이, 부트 하부에서 상부로 진행하는 수지흐름과 부트 측면에서좌우로 회전하 는 흐름의 충돌 패턴이 확인되었고 이러한 충돌 패턴으로 인하여 weld 및 meld line 형성 가능성이 크기 때문에 흐름충돌이 없는 충전 패턴의 형성을 위해서 각각 다른 게이트 위치의 경우에 따른 사출성 형모사 및 해석을 수행하였다. 한편 가류층 비율(cured layer fraction) 분석에서는, Fig. 8 에서와 같이, 부트의 크랙이 발생하는 위치에서 가 류층 비율이 약 $60 \%$ 정도 밖에 되지 않음이 확인되었다. 따라서 몰 드 온도를 올림으로써 부트의 크랙이 발생하는 위치에서 $100 \%$ 의 가 류층 비율을 이루고자 하였다.

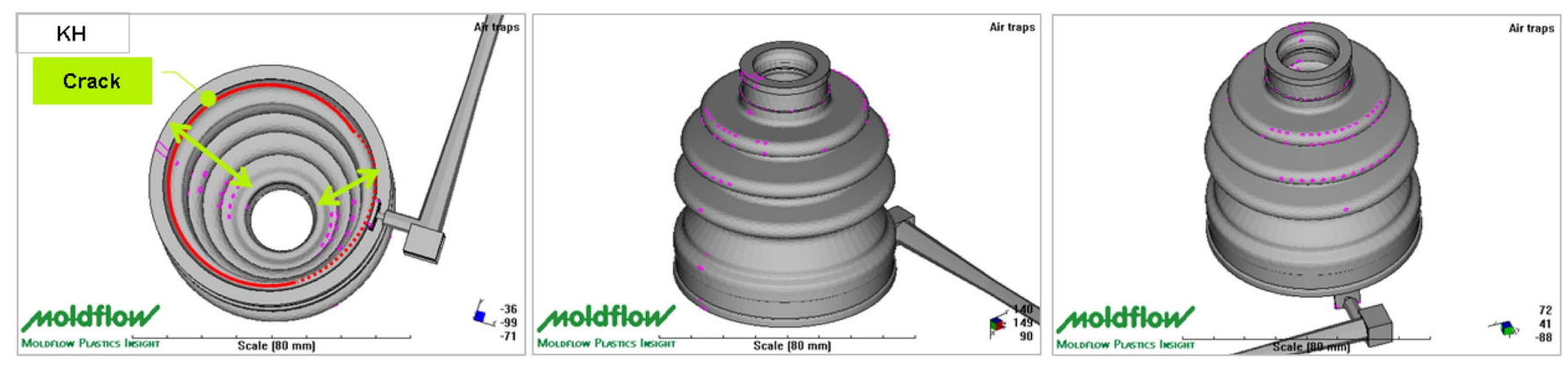

Fig. 5. Locations of air traps indicated from the simulation result of the current injection molding process for boots produced by $\mathrm{K}$ company.

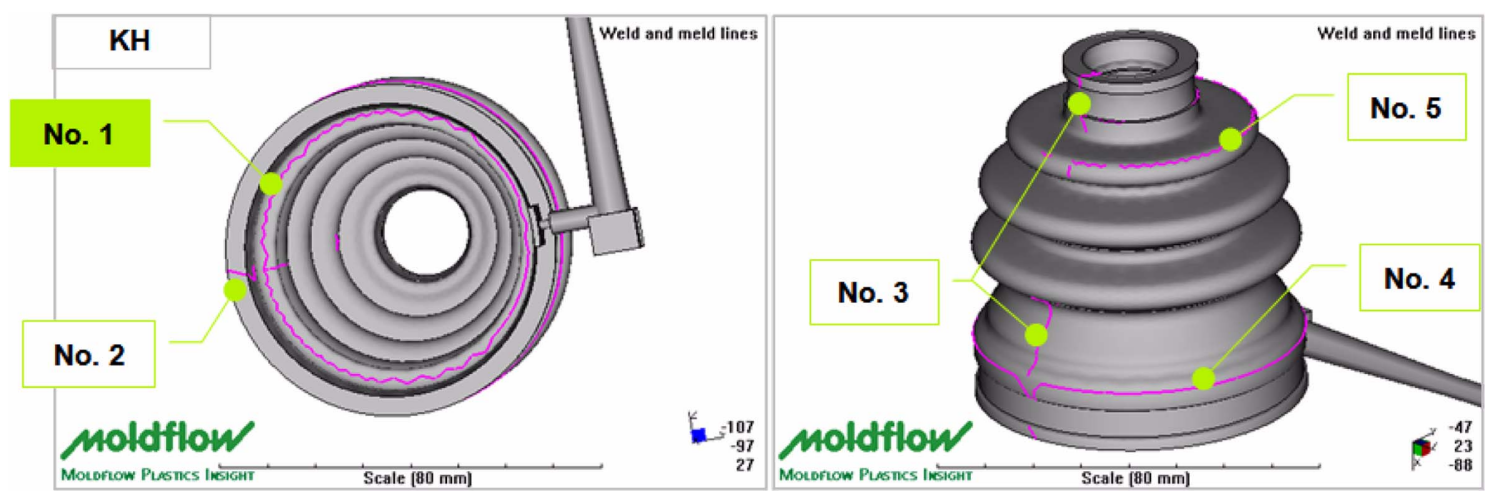

Fig. 6. Locations of major(No. 1) and minor(No. 2-5) weld and meld lines indicated from the simulation result of the current injection molding process for boots produced by $\mathrm{K}$ company.
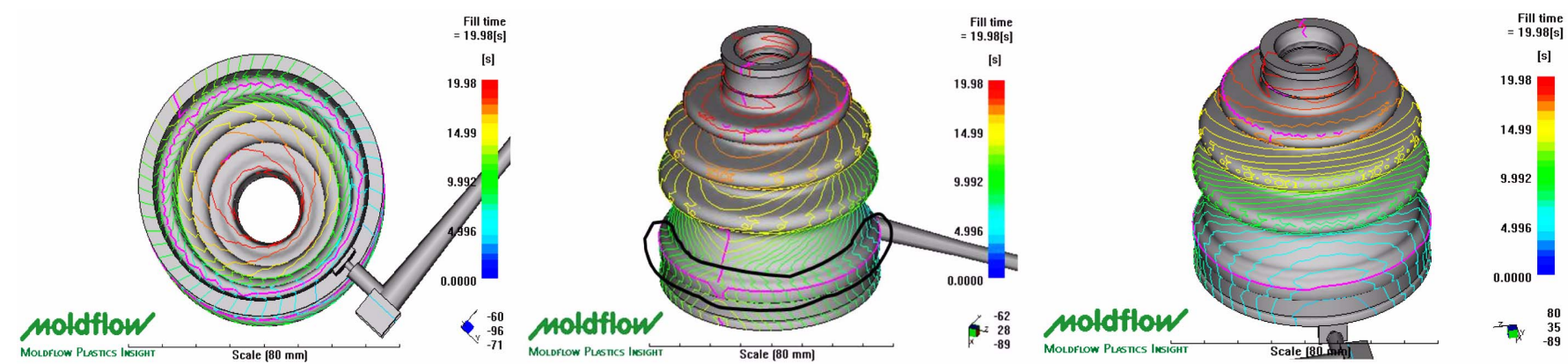

Fig. 7. Fill time analysis from the simulation result of the current injection molding process for boots produced by $\mathrm{K}$ company.

Korean Chem. Eng. Res., Vol. 49, No. 1, February, 2011 

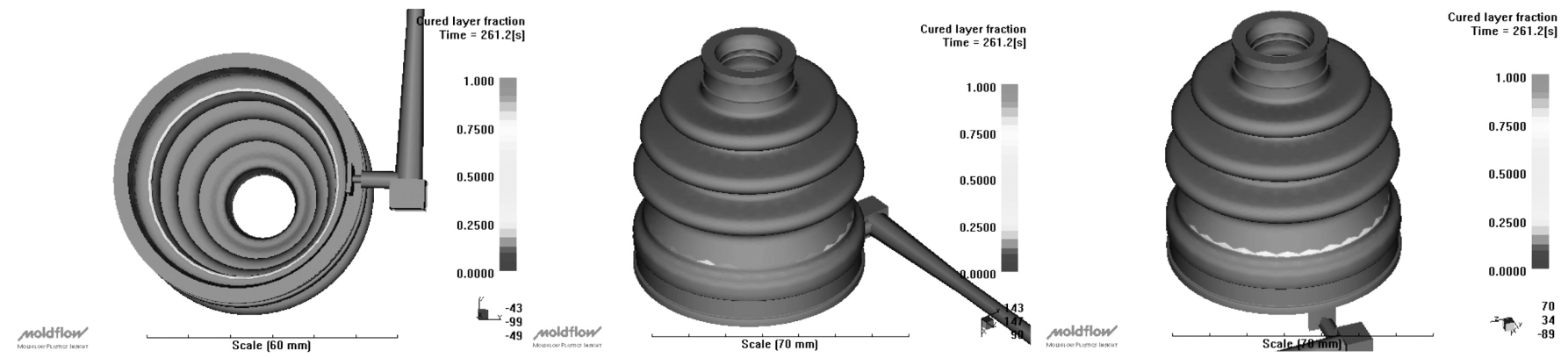

Fig. 8. Curing analysis from the simulation result of the current injection molding process for boots produced by K company.

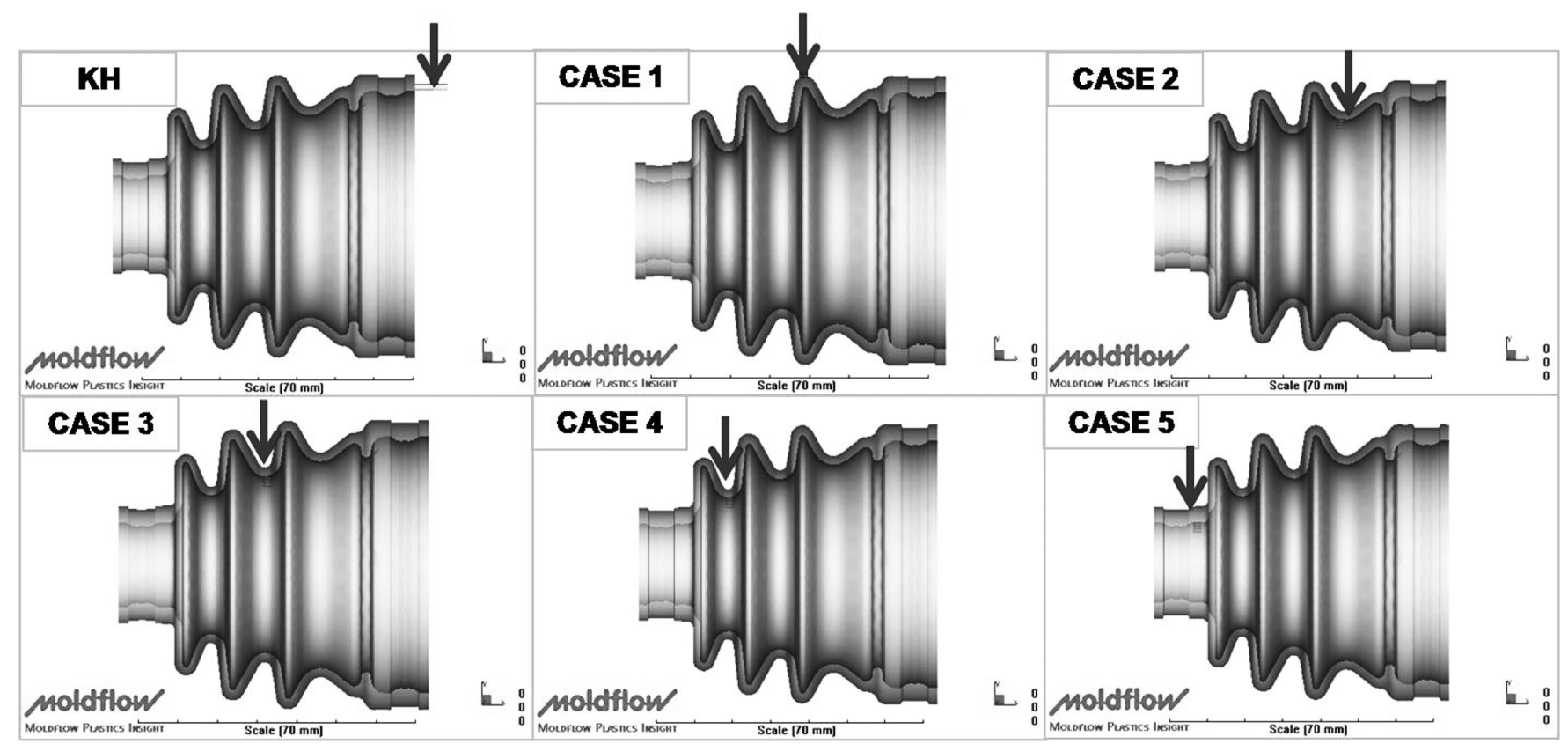

Fig. 9. Gate position(arrow) for the current injection molding process for boots produced by $\mathrm{K}$ company and the altered gate positions(arrow) for cases 1 through 5.

현재 K사에서 채택하고 있는 게이트 위치를 변경하여 Fig. 9와 같은 5 개의 서로 다른 게이트 위치에서 각각 모사 및 해석을 수행하여, weld 및 meld line과 에어트랩의 생성패턴을 Fig. 10과 11과 같이 각 각 관찰하였다(선정된 위치에 게이트를 설치함에 있어서, 실제 사출 성형에 있어서 코아(core) 금형의 내부로 게이트를 설치하는 것은 기 술적 및 경제적으로 어려운 점이 있어서 캐비티 바깥 금형에 게이트 설치하는 것이 선호된다). Fig. 12와 같이 게이트의 최적위치를 기준 점으로 오른쪽 방향 $(\mathrm{K}$ 사 게이트 위치 $)$ 으로는 $\mathrm{K}$ 사의 부트 결함과 일 치하는 심각한 weld 및 meld line과 미미한 에어트랩이 나타났고, 왼 쪽방향으로는 보통수준의 weld 및 meld line과 심각한 수준의 에어 트랩이 나타났다. 따라서 weld 및 meld line과 에어트랩(air trap) 불 량이 가장 큰 게이트 위치는 각각 최적 게이트위치를 기준으로 서로 정반대 방향임이 관찰되었다.

적정(optimum) 게이트 위치로서 case 1, 2 및 3으로 범위를 좁혀 서 $\mathrm{K}$ 사 경우 $(\mathrm{KH})$ 와 함께 충전시간(fill time) 패턴 및 압력분포 패턴 을 Figs. 13 및 14와 같이 각각 구하였다. 충전시간(fill time) 패턴에 서, $\mathrm{K}$ 사 경우 $(\mathrm{KH})$ 는 하부에서 상부로, 휘감아 올라가는 모습의 패턴 을 보였고, case 1, 2 및 3은 중부에서 상-하부로 진행하는 패턴으로, 마지막 충전단계에서 급속히 빠른 진행을 보이는 case 3 에 비해, case
1 및 2 는 전체적으로 안정된 패턴을 보였다. 이와 같이 case 1 및 2 에서의 게이트 위치의 최적화로 인한 개선된 충전패턴으로 weld 및 meld line 및 에어트랩의 문제를 해결하였다. 한편 몰드 온도를 $170{ }^{\circ} \mathrm{C}$ 로 $10^{\circ} \mathrm{C}$ 만큼 올림으로써, Fig. 8 에서와 같이 가류층 비율 (cured layer fraction) 분석에서 부트의 크랙이 발생하는 위치에서 약 $60 \%$ 정도 밖에 되지 않는 가류층 비율을 제고하여서 $100 \%$ 가류층 비율에 도달하였으나, $\mathrm{K}$ 사 경우 $(\mathrm{KH})$ 에는 Fig. 15 에서와 같이 크랙의 발생은 방지하지 못하였다. 그러나 case 1 의 경우에는 Fig. 16 과 같 이 $100 \%$ 가류층 비율과 함께 크랙 형성이 완전하게 방지됨이 관찰 되었다.

\section{4. 결 론}

$\mathrm{K}$ 사 부트의 결함인 크랙의 실제 발생위치와, $\mathrm{K}$ 사의 부트 사출성 형 공정조건 하에서 $\mathrm{MPI} /$ reactive molding 모듈을 사용하여 수행된 전산모사 결과에서 보여주는 주요 weld 및 meld line 생성위치가 일 치하였음이 관찰되었다. 한편 가류층 비율분석에서는 부트의 크랙이 발생하는 위치에서 가류층 비율이 약 $60 \%$ 정도 밖에 되지 않음을 보 여주었다. 따라서 $\mathrm{K}$ 사 부트 크랙의 발생원인은 weld 및 meld line의 


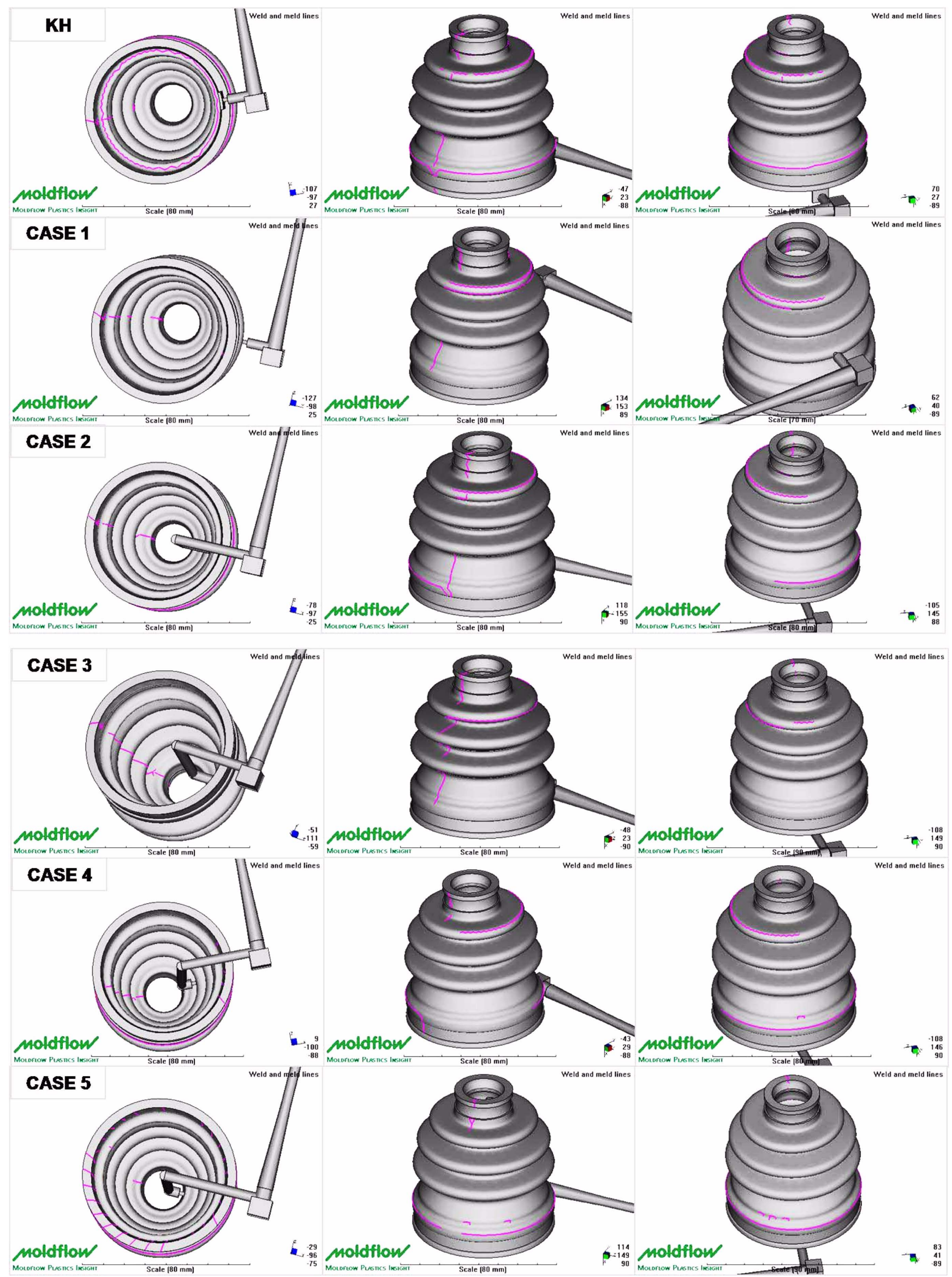

Fig. 10. Weld and meld line analysis for the gate positions of $\mathrm{K}$ company(KH) and cases 1 through 5.

Korean Chem. Eng. Res., Vol. 49, No. 1, February, 2011 


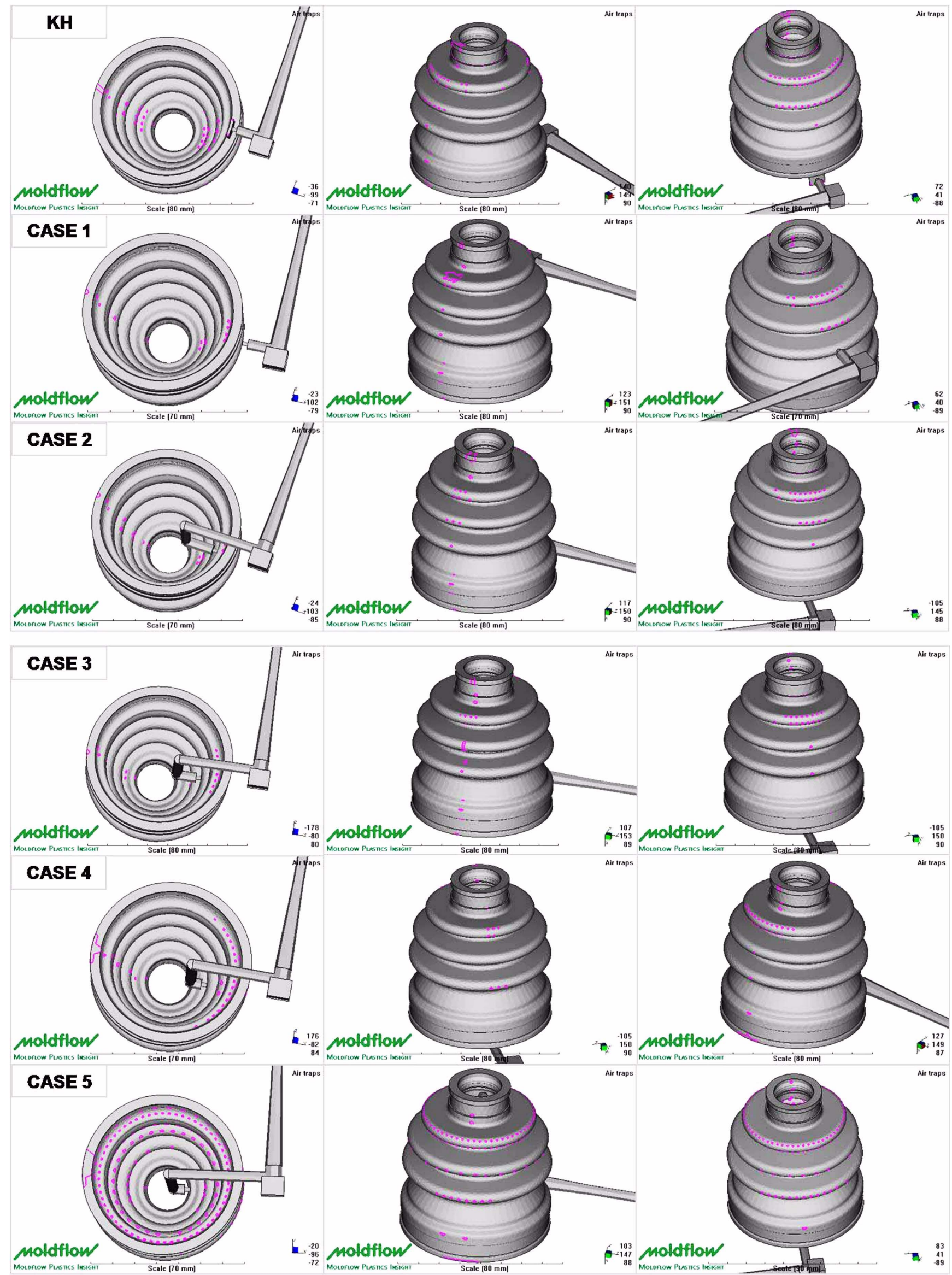

Fig. 11. Air trap analysis for the gate positions of $K$ company(KH) and cases 1 through 5. 


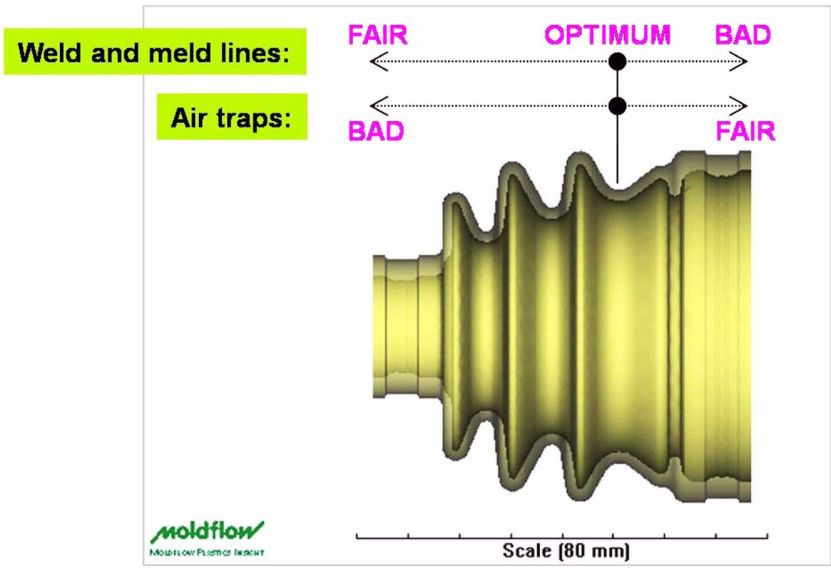

Fig. 12. Degree of the formation of weld and meld lines and air traps by altering gate positions.
생성에 기인한다고 간주되었고, 몰드 온도를 올림으로써 부트의 크 랙이 발생하는 위치에서 $100 \%$ 의 가류층 비율을 달성코자 하였다. 이 에 따라서 $\mathrm{K}$ 사에서 적용하고 있는 게이트 위치를 전산모사 결과에 서 제시하는 최적 게이트 위치로 변경하여 유동선단의 충돌 또는 흐 름의 만남이 최소화된 충전패턴을 형성함으로써, $\mathrm{K}$ 사 부트의 결함 인 부트 안쪽 하단의 크랙 생성을 방지하였다. 게이트의 최적위치를 기점으로 한쪽 방향 $(\mathrm{K}$ 사 게이트 위치 $)$ 에서는 $\mathrm{K}$ 사의 부트 결함과 일 치하는 심각한 weld 및 meld line과 미미한 에어트랩이 나타났고, 반 대방향으로는 보통수준의 weld 및 meld line과 심각한 수준의 에어 트랩 불량이 나타났다. 따라서 weld 및 meld line과 에어트랩(air trap) 불량이 가장 큰 게이트 위치는 각각 최적 게이트위치를 기준으로 서 로 정반대 방향임이 관찰되었다. 또한 몰드온도를 $160{ }^{\circ} \mathrm{C}$ 에서 $170{ }^{\circ} \mathrm{C}$ 로 $10{ }^{\circ} \mathrm{C}$ 만큼 높임으로써 가류층 비율을 $100 \%$ 에 도달하게 하였다.

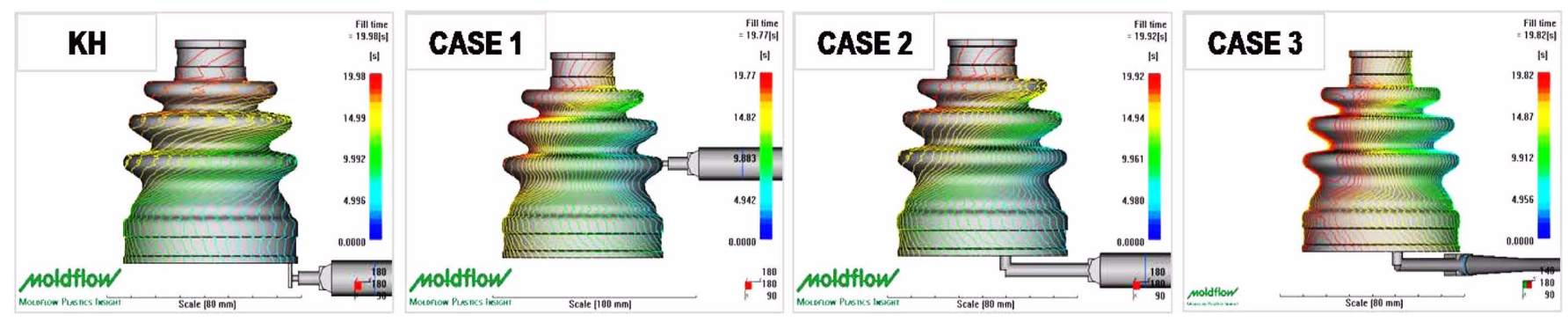

Fig. 13. Fill time analysis from the simulation result of the rubber injection molding process for boots with the gate positions of $\mathrm{K}$ company(KH) and cases 1 through 3.

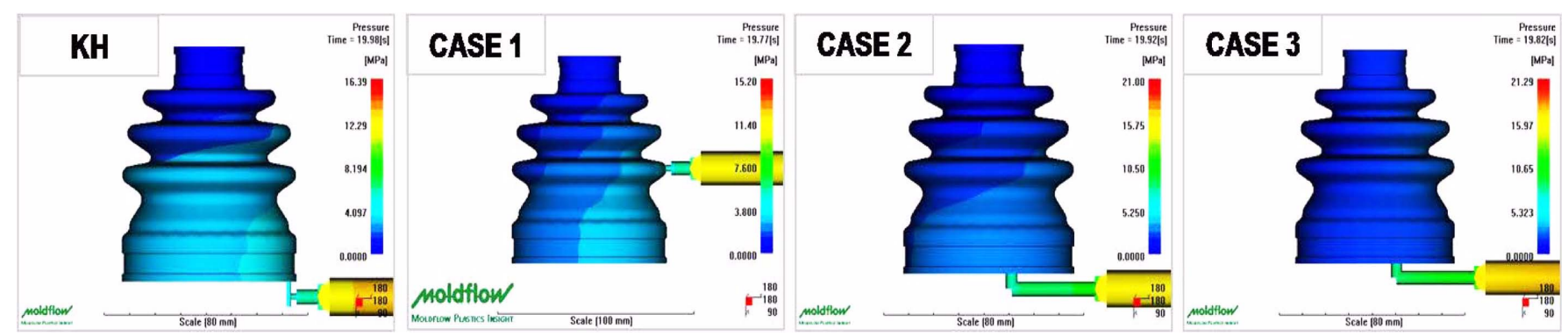

Fig. 14. Pressure time analysis from the simulation result of the rubber injection molding process for boots with the gate positions of $K$ company $(\mathrm{KH})$ and cases 1 through 3.

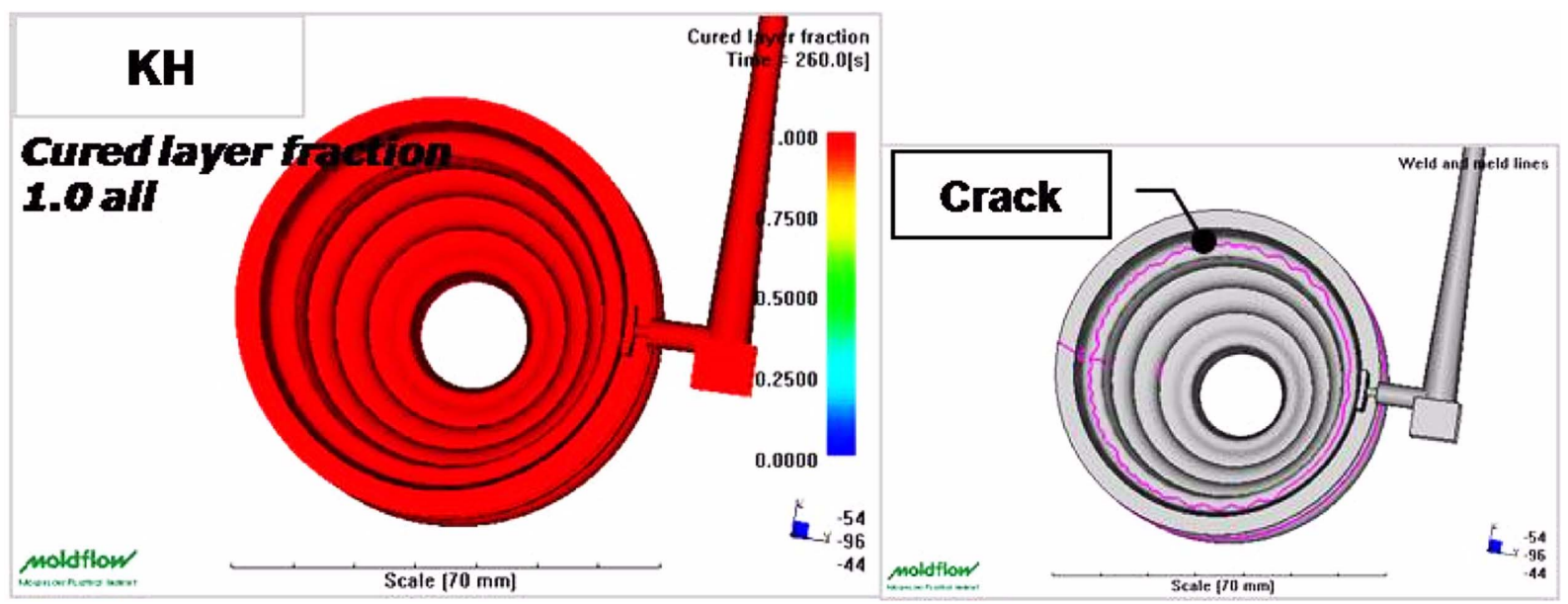

Fig. 15. Curing analysis from the simulation result of the rubber injection molding process for boots with the current gate position(KH) and the raised mold temperature of $170{ }^{\circ} \mathrm{C}$.

Korean Chem. Eng. Res., Vol. 49, No. 1, February, 2011 


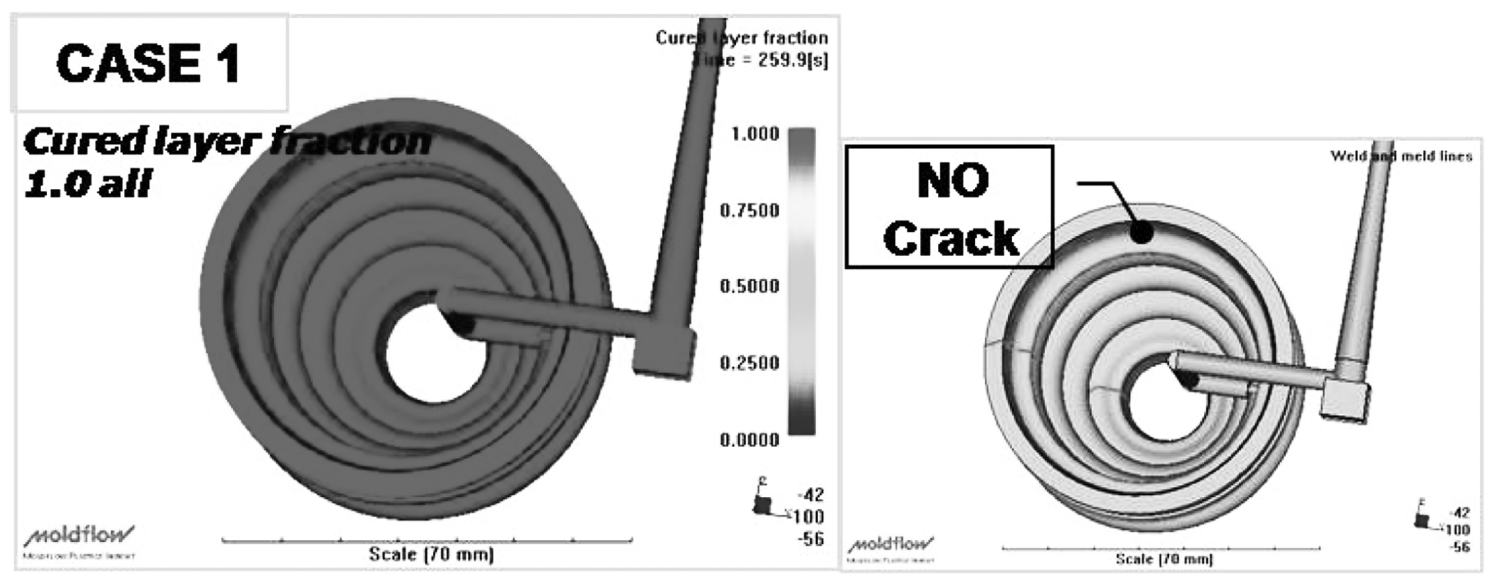

Fig. 16. Curing analysis from the simulation result of the rubber injection molding process for boots with the optimum gate position(case 1) and the raised mold temperature of $170^{\circ} \mathrm{C}$.

\section{참고문헌}

1. Ryu, I. H., Cho, J. and Lim, Y., "FE Anaysis of Clamping Process for Ear-Type Band of CV,' KSAE Symposium on driving and braking, September, Seoul(2007).

2. Lee, H. W., Kim, S. H., Lee, C. H., Huh, H., Lee, J. H. and Oh, S. T., "Finite Element Analysis for 3-D Self-Contact Problems of C. V. Joint Rubber Boots," Transactions of the KSME A, 21, 2121 (1997).

3. Lee, H.-W., Kim, S.-H. and Huh, H., "Finite Element Analysis of C. V. Joint Rubber Boot using Effective Treatment of Self Contact," Proceedings of KSME Spring Meetings A, April, Chonan (1999).

4. Harry, D. H. and Parrot, R. G., "Numerical Simulation of Injection Mold Filling," Polym. Eng. Sci., 10, 209 (1970).

5. Gao, F., Patterson, W. I. and Karmal, M. R., "Cavity Pressure Dynamics and Self-Tuning Control for Filling and Packing Phases of Thermoplastics Injection Molding," Polym. Eng. Sci., 36, 1272
(1996).

6. Lee, Y. B. and Kwon, T. H., "Modeling and Numerical Simulation of Residual Stresses and Birefringence in Injection Molded Centered-gated Disks," J. Mater. Process. Technol., 111, 214(2001).

7. Hieber, C. A. and Shen, S. F., "A Finite-element/Finite-difference Simulation of the Injection-molding Filling Process," J. Non-Newton. Fluid Mech., 7, 1(1980).

8. Tucker, C. Fundamentals of Computer Modeling for Polymer Processing, Hanser, Munich(1989).

9. Kennedy, P., Flow Analysis of Injection Molds, Hanser, Munich (1995).

10. Chiang, H. H., Hieber, C. A. and Wang, K. K., "A Unified Simulation of the Filling and Post-filling Stages in Injection Molding," Polym. Eng. Sci., 31, 116(1991).

11. Turng, L. S. and Wang, V. W., "On the Simulation of Microelectric Encapsulation with Epoxy Molding Compound,'J. Reinf. Plast. Compos., 12, 506(1993). 